\title{
Research on Reflection and Practice on Reform of College Chinese Teaching
}

\author{
Lin Wei \\ Chongqing Three Gorges Medical College, Chongqing, China \\ 22879738@qq.com
}

Keywords: College Chinese; Teaching Reform; Internet Teaching Platform

\begin{abstract}
College Chinese as an important course of college students' humanistic accomplishment is conducive to promoting the development of college students. Based on the full development of college students, this paper analyzes the problems existing in the current college Chinese teaching and expounds the significance of the development of college students. On the basis of the characteristics of college Chinese teaching, this paper puts forward the ideas of College Chinese reform and Suggest. This paper puts forward some suggestions on the teaching of Chinese teaching in order to improve the role of college students' humanistic spirit and Chinese language teaching. Strengthen the teacher's teaching reform consciousness, university language should be clear curriculum orientation, adhere to the unity of instrumentality and humanities, improve the overall cultural accomplishment of students, shaping students noble humanistic spirit and personality; focus on the study of students' existing knowledge structure, innovation university Language teaching reform methods to improve teaching effectiveness.
\end{abstract}

\section{Theoretical Introduction of College Chinese}

College Chinese in order to make our contemporary college students become a comprehensive combination of arts and literature talent, is based on the university language curriculum as the carrier, effectively cultivate contemporary college students humane care and its understanding of society, learn humanistic thinking of the trial and training and ability. In addition to improve the ability of students to use language, the university language teaching must not be confined to the high school language teaching u language sentence interpretation, as well as the inheritance of the traditional Chinese culture to carry forward, cultivate the promotion of college students The role of moral character.

We must take on the inheritance and development of the traditional Chinese literature and take on the spread and introduction of the outstanding cultural traditions of all ethnic groups in the world, so that our contemporary college students have a sense of mission from the national tradition. Especially the Chinese language curriculum in the Chinese and foreign literature classics, for the nourishment of college students ideological and sentiment, has a very important significance ${ }^{[1]}$.

The university language shoulders the mission of cultivating the humanistic accomplishment and moral sentiment of the contemporary college students, and also bear the inheritance and development of the famous and famous literature of ancient and modern Chinese and foreign literature. Therefore, the teaching reform and practice of college Chinese course is a very large systematic project, which involves many aspects of the orientation of Chinese language curriculum, teaching reform and so on. Moreover, the reform of college Chinese teaching must be combined with the final practice effect, so that the course set up, effectively play for the contemporary college students to improve the quality of humanities, language and language applications to enhance the ability to make the final Chinese language courses Can become a culture of contemporary college students comprehensive quality, comprehensive strength of the media.

\section{Content of College Chinese Teaching Reform}

In the new Chinese language and literature undergraduate training program, the original 72 hours of language teaching method is divided into Chinese language curriculum and teaching theory, 
compulsory 72 hours, while opening a series of Chinese language and literature undergraduate training program, elective courses, the establishment of a relatively complete language education curriculum system ${ }^{[2]}$.

First of all, the principle of inheritance and innovation, the teaching content of the course and the teaching course of the course, the basic knowledge of curriculum and teaching theory, the elements and structure of the curriculum goal of the new century, the "high school curriculum" and "high school Chinese language curriculum standards "interpretation, high school Chinese new curriculum materials, reading teaching dialogue theory, the text as the core of the multiple interpretation theory, personalized reading and personalized composition, comprehensive language learning, language new curriculum teaching evaluation and so on Chinese courses and teaching theory, replaced the original outdated content. In order to achieve the desired purpose, we must first deal with the following relationship: firstly, deal with theoretical study and practical skills training relationship. On one hand we have increased the practice time, on the other hand the theoretical study and the practice training are carried out simultaneously.

Through the content adjustment, in addition to guarantee the language teaching skills training class in-class training, the teaching materials research report writing and lesson plans are all changed in extracurricular; the middle school language teaching observation, awareness and skills sub-training content Language courses and teaching theory of learning, the effect is very obvious. The new language curriculum standards proposed to actively promote the "autonomy, cooperation, explore" learning. Especially in the teaching materials research, teaching ability training, lesson plans and trial process, the effect is very good. In order to mobilize the enthusiasm and initiative of the students in the practice of Chinese teaching practice, deepen the rational understanding of the Chinese language curriculum and teaching theory, and strengthen the students' ability of teaching and practicing Chinese language, in order to cultivate students' ability to solve problems and to cultivate students' ability to solve problems ${ }^{[3]}$.

\section{Strategies and Methods of Teaching Reform}

In the full-time colleges and universities to set up university language courses, the fundamental purpose is: give full play to the humanities of the humanities and instrumental characteristics, to adapt to contemporary humanities and natural science increasingly cross infiltration. So we should position it in the cultivation of students' literature and art appreciation ability, so that students through the reading and appreciation of literary works to enhance their literary knowledge, and enrich emotional experience to improve their aesthetic ability and writing ability ${ }^{[4]}$. Fig.1 shows strategies and methods of teaching reform.

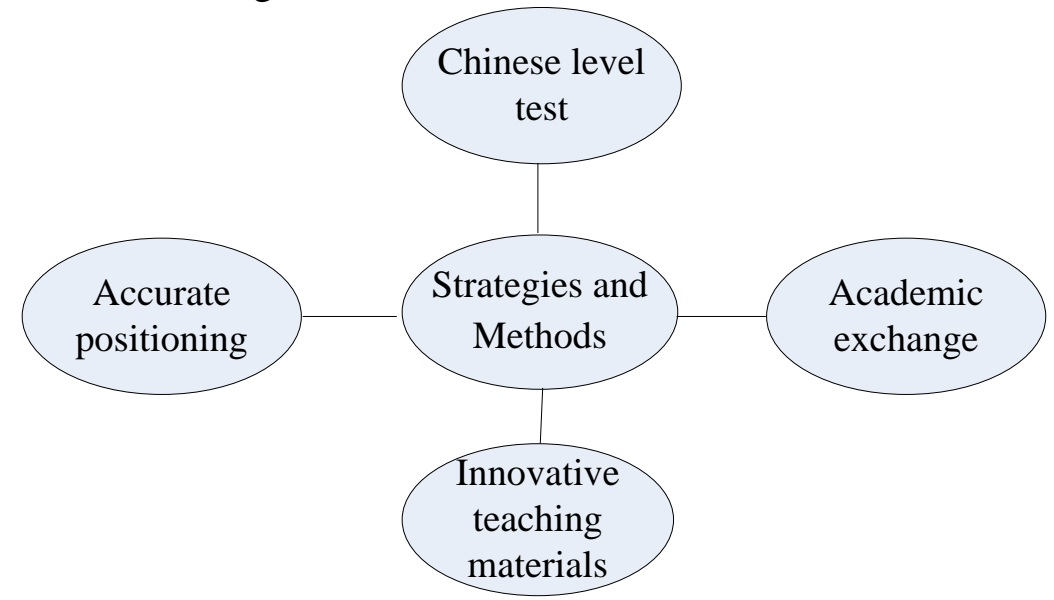

Fig. 1.Strategies and methods of teaching reform

College Chinese teaching materials should be those in the content of the performance of openness and integrity, in the system pay attention to the combination of macro and micro, in the emphasis on open and inspiring College Chinese new textbooks. In short, the construction of university language teaching materials should be human, aesthetic, interesting, instrumental, new 
classic unity. University language is a public foundation for the whole hospital, get the attention of teachers and students, first of all to get the school leaders attach importance to the university language is limited, the school teaching management department to take into account the characteristics of College Chinese teaching, as far as possible into a small class, so that students in the quiet environment to learn to appreciate and heart and heart of the exchange.

Strengthen the teacher building and academic exchanges, and actively create a harmonious atmosphere of university language health, teachers should have a broad background of knowledge with a strong sense of the text that is the ability to analyze works, through the application of network courseware to develop horizontal thinking mode, should be from the abstract text Symbols and understand the rich connotation of association. As in college English four or six examinations, the university language teaching is also included in the examination grade system, thus contributing to the university language and society as a whole to improve the quality of language. Teachers of this dominant factor to set up a new teaching philosophy, College Chinese should be accurate positioning, and as an opportunity to stimulate students' interest in learning, to seize the teaching of teaching and learning the two subjects we believe that the university language teaching will be With another new face appearing in college class.

\section{The Internet Teaching Platform}

Learning platform via the Internet, learners can view various types of quality teaching resources, teachers can learners learning process, the number of online, long effective monitoring at logon, administrators can teaching activities Primary School to regulate guidance and better optimization classroom, so as to enhance the overall level. Although the Internet learning platform is more mature application platform, but its ongoing maintenance and functional expansion is still a top priority. Internet-based learning platform as the base camp, the platform, still needs to make further efforts in terms of cross-platform compatibility ${ }^{[5]}$. Fig.2 shows the Internet teaching platform.

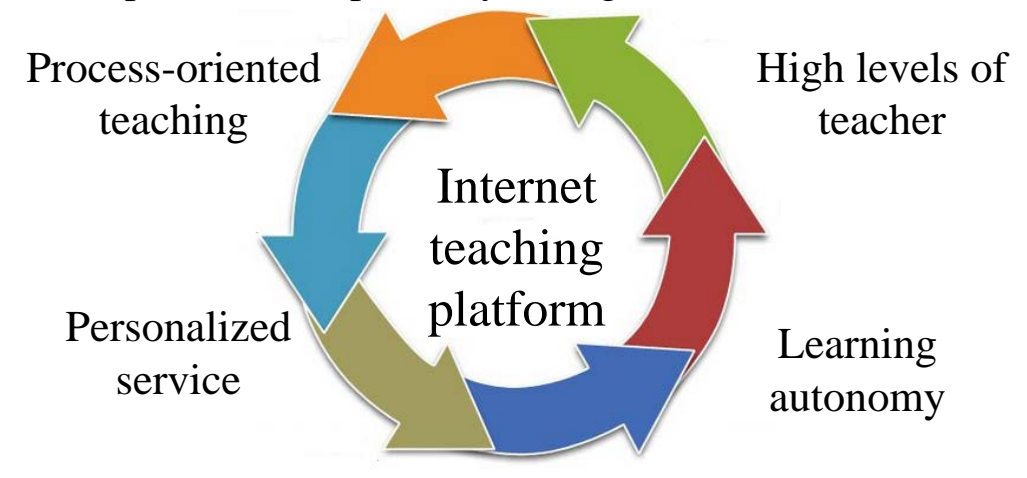

Fig. 2.The Internet teaching platform

Instructional design streamlined. Teaching process design according to the characteristics of each course, the teaching process need modular, each module teaching activities require concrete. Each module can only enter after learning tasks to complete the next learning module, in order to achieve the purpose to enhance learning. Through the process of instructional design, the learner can complete each course in accordance with the requirements step by step. Because of individual differences in the level of knowledge of learners, different learning requirements of learners, acceptance and achievable goals are different. To form a variety of hierarchical menus to learners alternative course guidelines, including an overview of the course, objectives, content, assessment plan, implementation of the recommendations, etc., in order to meet the individual and diverse teaching management. In addition, the platform can be developed for learners personalized content for learners' learning behavior data mining, to distinguish patterns of behavior of learners, learning preferences.

Independent learning learners, through the process of teaching, order management, individualized services and other measures to address the students' self-directed learning, self-monitoring, self-evaluation and other issues. Teaching management platform can also help learners to form correct self-learning method. Learners can be customized personalized service and 
subscribe to your attention the content according to their actual situation, truly autonomous learning. Distance education is a higher, more stringent requirement for teachers. Distance education teachers should not only have deep expertise, a broad range of scientific and cultural knowledge, but also has to help learners to self-monitoring and self-evaluation capabilities. Open University should be the selection, training a large number of outstanding teachers, enhance the core competitiveness of the school, which is also essential for teaching management.

\section{Conclusions}

The basic task of higher education is to cultivate all the compound talents, to promote the development of college students, and university language as an important content of higher education, college students and the development of humanistic basis. College Chinese curriculum, we must attach importance to the cultivation of humanities education and humanistic spirit, and improve the humanistic quality of contemporary college students. The overall goal is to improve the quality of college students and the humanistic spirit. College Chinese classes must be in the practice of teaching reform does not adapt to the current situation of the teaching model and methods in order to improve the enthusiasm of college students to learn, but also in improving the quality of college students to play its unique role. College Chinese teaching reform can effectively improve the ability of college students to use language, reading and appreciation ability, until the effective promotion of contemporary college students, such as customs training, human feelings, moral sentiment and other intrinsic spiritual accomplishment.

\section{Reference}

[1] Liu Li, campus culture construction [J], Journal of Chongqing Institute of Technology 2006 (10): 157.

[2] Chen Zhao Jin. Rethinking the nature of university language and teaching reform [J]. Chinese Journal of Higher Education, 2007 (3): 71.

[3] Hong Ye. University Language Teaching and Reform [J]. Guizhou Police Officer Vocational College, 2006 (02).

[4] Yu Qiao Yan. Out of the difficulties of humanistic education in the university [J].Hebei Higher Education Research, 2008 (03).

[5] Lan Shi Ying. University of Language and Literature Studies teachers' role in the problem [J], Jiangsu Teachers University of Technology, 2011 (11): 101. 